Recibido: 19-noviembre-2013

Aceptado: 28-noviembre-2013

\title{
ESTUDIO DE NAVEGABILIDAD DEL RÍO BOBONAZA DESDE CANELOS (PUERTO LATASAS) HASTA SARAYACU, PRIMERA ETAPA
}

\author{
MÓNICA CORONEL \\ CETIFF \\ Universidad Central del Ecuador \\ JHON O. USIÑA P. \\ CETIF \\ Universidad Central del Ecuador
}




\section{RESUMEN}

El estudio está orientado a analizar las condiciones de navegabilidad del río Bobonaza, el cual servirá de base para investigaciones futuras sobre la navegabilidad de los ríos de la Amazonía, ya que en el país no existen estudios similares y por lo tanto, el presente trabajo constituye un gran aporte a los objetivos de desarrollo nacional y principalmente permite orientar el apoyo a las comunidades asentadas a lo largo de las riberas del río Bobonaza, entendiendo que el transporte fluvial es un servicio fundamental para despuntar el desarrollo local y regional. Como investigaciones de soporte fueron necesarios los estudios correspondientes a las áreas social, económica y ambiental; información que permite conocer los parámetros más incidentes en la navegabilidad del río Bobonaza, pues exponen la realidad en la que viven y las diferentes necesidades de los habitantes de la zona de influencia, respecto fundamentalmente a movilidad, condiciones de ocupación, empleo, escolaridad, nivel de pobreza, patrimonio natural, entre otras.

Palabras clave: estudio, navegabilidad, río Bobonaza, Canelos, Sarayacu, transporte, hidráulica, área social, área económica, ambiental, desarrollo local.

\section{ABSTRACT}

This study is aimed to analyze the navigability of Bobonaza River which serves as a basis for future research on the navigability of the rivers of the Amazon. Since the country has no similar studies the present work is a great contribution to the national development objectives and primarily to guide supporting the communities living along the banks of the river Bobonaza, understanding that river transport is a fundamental means of local and regional development service. Information that allows to know the parameters of Bobonaza river navigability, the reality in which they live, the different needs of the citizens and a research support of the social, economic and environmental areas were necessary hinterland, mainly regarding to mobility, employment conditions, education, poverty, natural heritage, among others.

Keywords: study, navigation, Bobonaza river, Canelos, Sarayacu, transport, hydraulic, social area, area economic, environmental, development local words. 


\section{PREÁMBULO}

El desarrollo de la región amazónica ecuatoriana (RAE) y específicamente de la población que la habita, se logrará con la provisión de servicios e infraestructura de soporte para el transporte, agua potable, electricidad, alcantarillado, educación, salud, telecomunicaciones, entre otros.

La Región Amazónica ecuatoriana al formar parte del pulmón del mundo debido a su oxigeno, debe ser cuidada al máximo, y para dotarla de dichos servicios habrá que realizar estudios técnicos, con tecnologías amigables con el medio ambiente en procura de minimizar los impactos negativos que inevitablemente genera todo proceso de desarrollo al servicio de la actividad humana.

El estudio está orientado a analizar las condiciones de navegabilidad del río Bobonaza. Empero un estudio de esta naturaleza no se puede hacer con información muy limitada, sino que es necesario contar con información hidrológica histórica no menos de diez años y con registros batimétricos por lo menos tres veces al año, especialmente en épocas de creciente y de estiaje, sin embargo, al existir el apoyo del Instituto para el Ecodesarrollo de la Región Amazónica (ECORAE), se planteó realizar un estudio preliminar y que sirva de base para investigaciones futuras sobre la navegabilidad de los ríos de la Amazonía, ya que en el país no existen estudios similares y por lo tanto, el presente trabajo se constituye un gran aporte a los objetivos de desarrollo nacional y principalmente permite orientar el apoyo a las comunidades asentadas a lo largo de las riberas del río Bobonaza, entendiendo que el transporte fluvial es un servicio fundamental para despuntar el desarrollo local y regional.

En el levantamiento de información de campo desde Puerto Latasas hasta Sarayacu, siguiendo el curso del río Bobonaza, se evidenció que existen profundidades tan bajas del río que una canoa de madera, con eslora de $8 \mathrm{~m}$, puntal de $0,60 \mathrm{~m}$ y manga de $0,60 \mathrm{~m}$ encalló en más de cuarenta puntos del río; considerando un número de 8 pasajeros y carga ligera, haciendo del transporte -en el tramo de estudio- una actividad complicada, especialmente porque en el río no existe un thalweg definido, debido a la presencia de piedras de diferente tamaño, tornándose la navegación técnicamente imposible; no obstante, debido a la necesidad de movilizarse, a pesar de los riesgos inmersos, los habitantes de la zona se han acoplado al modo de transporte, y lo han hecho de tal manera que tienen la suficiente experticia para transitar por el río en condiciones muy críticas.

En tal sentido, para afrontar este problema en cierta parte y mejorar las condiciones de navegación, ante la necesidad de movilización, se recomienda llevar a cabo algunas alternativas de solución, como limpieza manual de piedras, construcción de espigones cortos, enrocado y limpieza mecánica del río, especialmente donde se determinó zonas de malos pasos, todas estas alternativas en procura de conformar un mínimo canal de navegación. Pero al ser un río en el cual existen varios rápidos, que hacen que se genere energía cinética aumento de velocidad del cauce- la navegación se vuelve peligrosa, principalmente en aquellas partes del río (malos pasos) con profundidades menores a $0,40 \mathrm{~m}$. Este fenómeno hidráulico demuestra una aceleración súbita de la velocidad, siendo difícil de corregir sin cambiar la morfología del 
río, por lo que se recomienda además, que la navegación se realice con motoristas que tengan alta experiencia y grado de responsabilidad, haciendo uso de chalecos salvavidas tanto para pasajeros como para tripulantes y provistos de un botiquín de primeros auxilios.

Asimismo, como investigaciones de soporte fueron necesarios los estudios correspondientes a las áreas social, económica y ambiental; información que permite conocer los parámetros más incidentes en la navegabilidad del río Bobonaza, pues exponen la realidad en la que viven y las diferentes necesidades de los habitantes de la zona de influencia, respecto fundamentalmente a movilidad, condiciones de ocupación, empleo, escolaridad, nivel de pobreza, patrimonio natural, entre otras. tan el calado de las embarcaciones, peligros a la navegación como: palos incrustados en el lecho, transporte de palizadas, meandros muy cerrados que restringen la eslora de las embarcaciones, canales de navegación cambiantes, entre otros.

Considerando la importancia del transporte fluvial para la integración amazónica y a fin de generar el desarrollo local en la región, se realizó el estudio de navegabilidad del río Bobonaza desde Canelos (Puerto Latasas) hasta Sarayacu - primera etapa, en la provincia de Pastaza. Este estudio se lo hizo con miras a construir una vía navegable atrayente a las necesidades del comercio interno de las comunidades dentro de la zona de influencia.

\subsection{Objetivos del estudio}

\section{SPECTOS GENERALES}

\subsection{Antecedentes}

La región amazónica, debido a su posición geográfica y a sus características naturales muy peculiares (clima, topografía, vegetación, hidrología, fragilidad ambiental, etc.), así como por la escasa inversión en infraestructura de soporte, no cuenta en la mayor parte de su extensión con vías terrestres o con infraestructura para transporte aéreo y fluvial suficientes, que permitan un eficiente transporte de carga y pasajeros entre los diferentes poblados que se encuentran en ella.

El principal medio de transporte en la Amazonía es el transporte fluvial a través de los ríos, sin embargo, debido a la dinámica de los mismos, la navegación fluvial se ve limitada, entre otros factores, por obstáculos naturales a la navegación, tales como: bancos de arena y piedras que limi-
Realizar el estudio de navegabilidad del río Bobonaza, desde Canelos (Puerto Latasas) hasta la comunidad de Sarayacu, provincia de Pastaza.

\section{Objetivos específicos}

- Establecer criterios hidrológicos e hidráulicos, parámetros de señalización de la ruta fluvial, obras de protección y encauzamiento del río.

- Determinar parámetros que permitirán promover el uso racional y ordenado de una navegación fluvial segura, preservando el medio ambiente e incentivando intercambios comerciales locales y regionales entre las comunidades asentadas a lo largo del río Bobonaza. 
- Ubicar y caracterizar los obstáculos a la navegación, considerando embarcaciones para el transporte de pasajeros y carga de distintas combinaciones.

- Identificar centros de producción y consumo.

- Evaluar y determinar las embarcaciones actuales que se encuentran en el medio y cuáles serían las adecuadas a implementar teniendo en cuenta las características del río, incluyendo costos de transporte fluvial y logística.

- Elaborar un plan de inversiones, identificando los requerimientos tecnológicos e infraestructura en general para desarrollar el corredor intermodal de transporte de pasajeros y carga.

- Elaborar un plan de manejo ambiental que posea medidas mitigadoras a ser aplicadas para solventar los impactos ambientales en el tramo en estudio. (puerto Latasas) coordenadas UTM (9823574.951N - 8200069.423E), cota 426,447 msnm y Sarayacu coordenadas UTM (9807435.144N - 8223476.124E) cota $358,703 \mathrm{msnm}$, con una longitud aproximada de $67 \mathrm{~km}$.

El río Bobonaza nace en las faldas de la Cordillera de Singui, entre los principales afluentes que aportan a este río, hasta llegar a la comunidad de Sarayacu se tiene: Tinguinza, Lupambi, Pavayacu, Aulapi, Cashpipitishca, Huamupi, Chambira, Lisanyacu, Landapi Salsapi, Ushillazazapi, Jatunzazapi, Calmito, Yatapiyacu, y Balsayacu, durante su recorrido pasa por las poblaciones de Canelos, Humupi, Chapetón, Pacayacu, Sarayacu, Montalvo, etc., hasta desembocar en el río Pastaza en la frontera entre Ecuador y Perú.

El régimen de sus aguas tiene dos épocas perfectamente diferenciadas: las crecientes que se presentan en los meses de abril y junio, mientras que el estiaje se presenta en los meses de julio y agosto.

\subsection{Ubicación del estudio}

El tramo del río Bobonaza objeto de estudio se encuentra ubicado en la Provincia de Pastaza, entre las parroquias de Canelos

Figura 1. 1 Ubicación del estudio de navegabilidad del río Bobonaza 


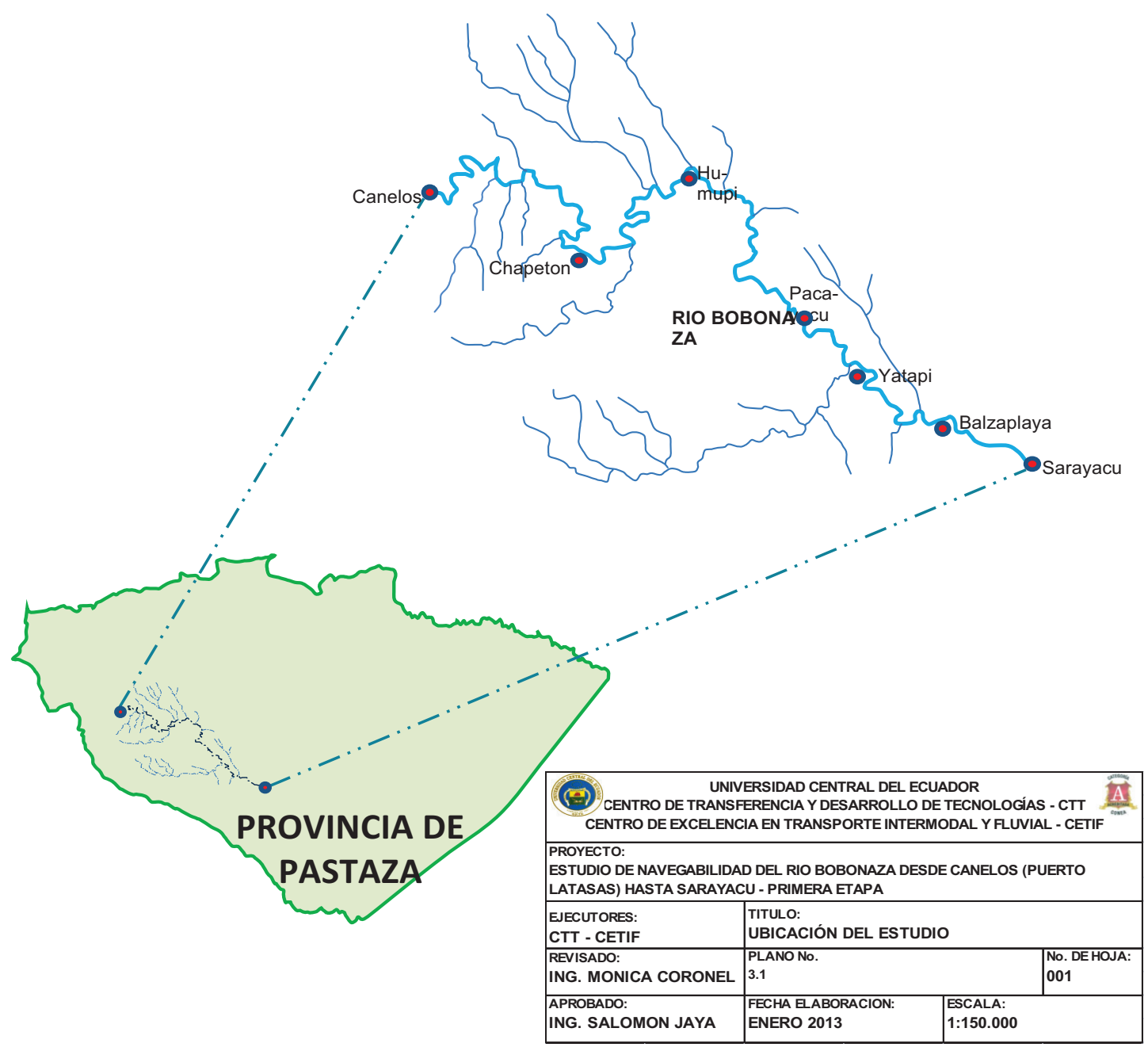

Elaboración: CETIF - UCE

\subsection{1 Área de influencia directa}

El área de influencia del presente estudio abarca aquellas zonas hídricas y terrestres en las que las acciones previstas para el desarrollo del Estudio de Navegabilidad del río Bobonaza pudieran alterar o generar flujos de tráfico e incidir en la actividad productiva, ambiental y social del sector.

Mediante el trabajo de campo realizado en la zona de estudio, el equipo técnico con- sultor determinó un área de influencia directa de aproximadamente $1 \mathrm{~km}$ desde el eje del río Bobonaza, hacia sus márgenes izquierda y derecha, considerando la accesibilidad fluvial y terrestre por medio de vías naturales de comunicación de los diversos poblados ubicados en las márgenes del río Bobonaza. 


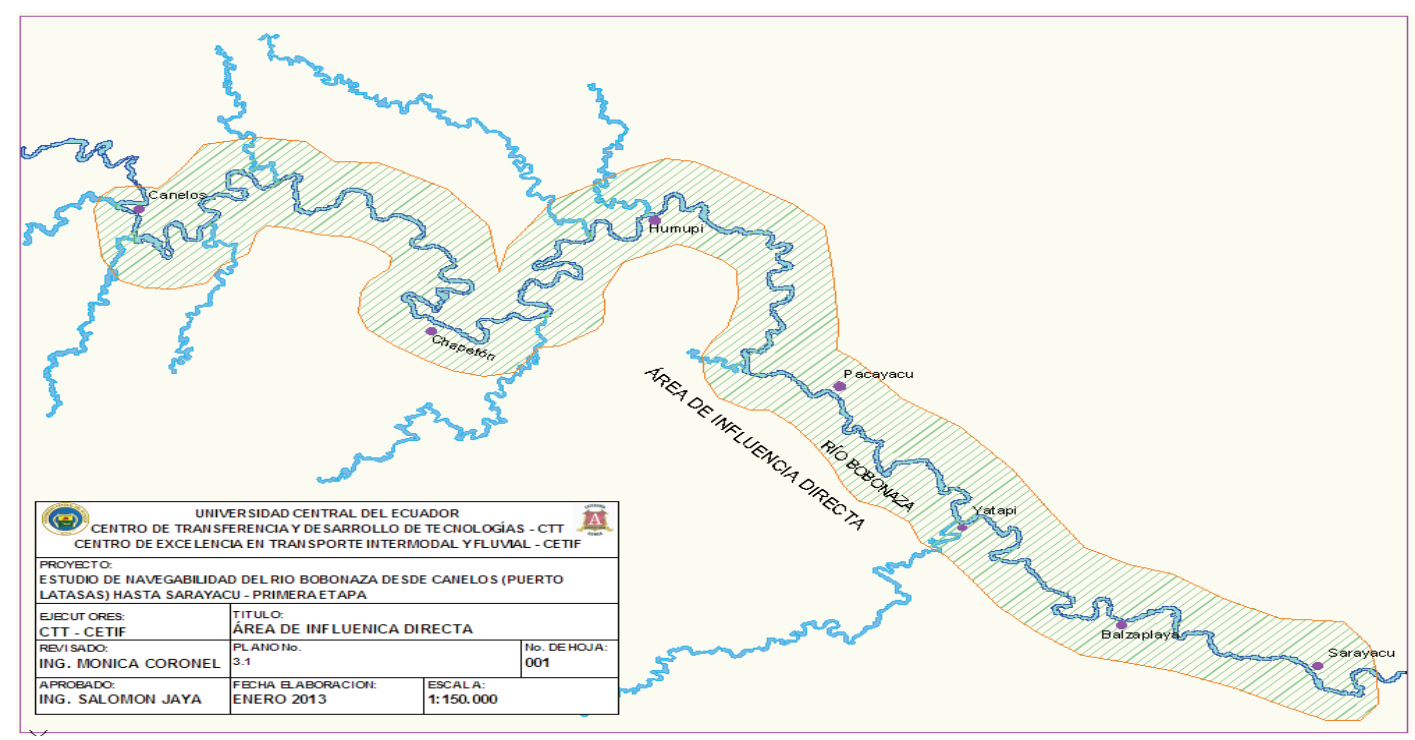

Elaboración: CETIF - UCE

Figura No. 1. 2 Área de Influencia directa

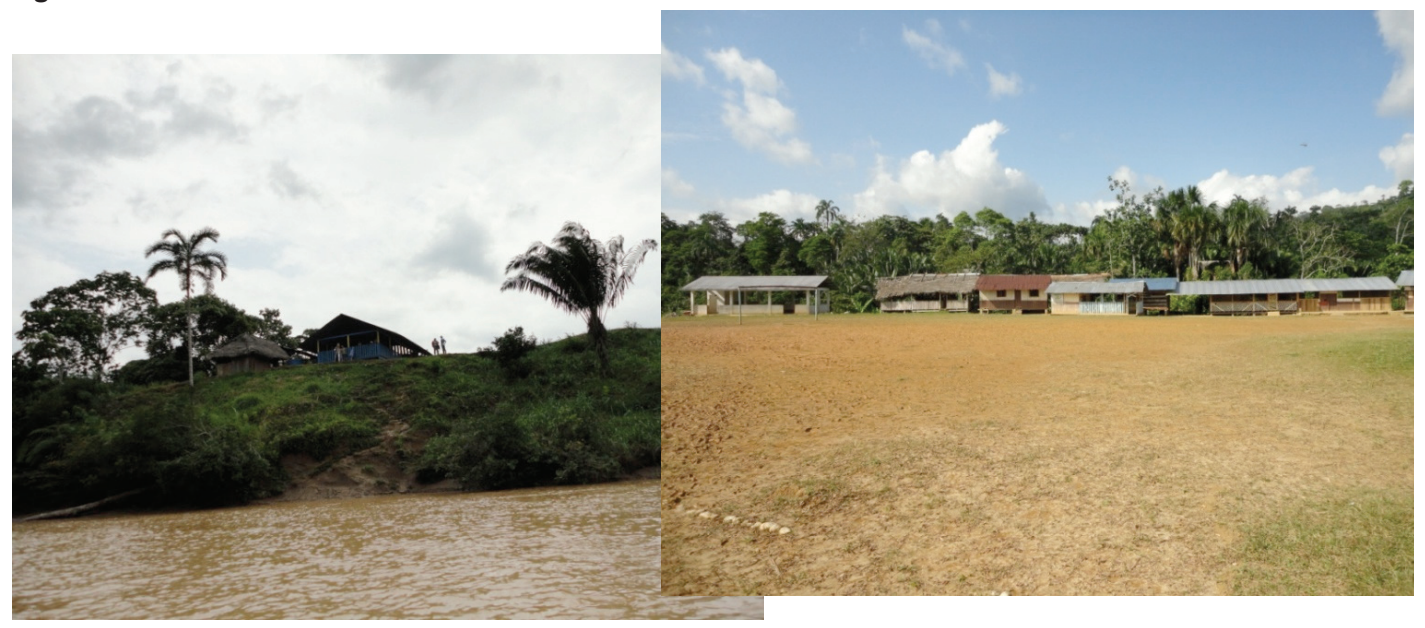

Fotografía 1. 1. Viviendas existentes a la ribera del río Bobonaza.
Fotografía 1. 2. Viviendas sobre la ribera del río Bobonaza. 


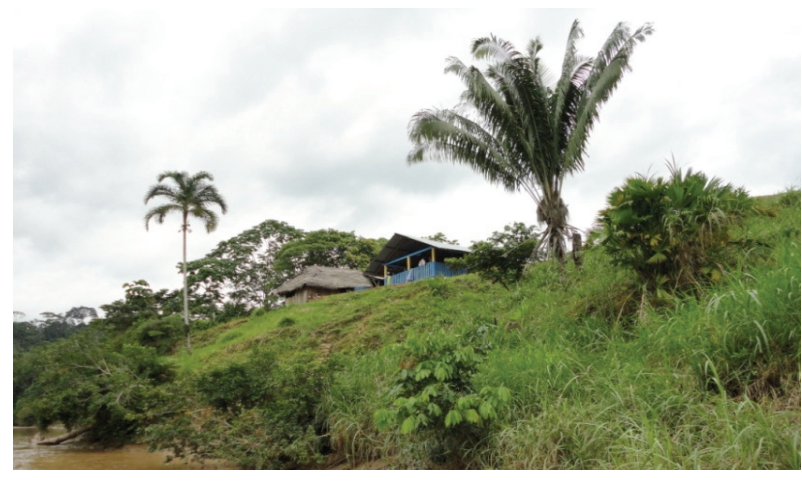

Fotografía 1. 3 Viviendas a la ribera del río Bobonaza.

\subsection{2 Área de Influencia Indirecta}

El área de influencia indirecta corresponde al espacio geográfico que esta fuera del Área de Influencia Directa, pero que de cierta manera podría verse influenciado por el estudio. Dentro de esta Área de Influencia Indirecta se encuentran las parroquias de Canelos ubicada aguas arriba de Puerto Latasas, la parroquia de Montalvo ubicada aguas abajo de Sarayacu, y demás comunidades y sectores que indirectamente se benefician con el estudio.

\subsubsection{Identificación de localidades dentro del tramo Puerto Latasas- Sarayacu}

La identificación de las localidades que se encuentran asentadas en las riberas del río Bobonaza en el tramo puerto Latasas hasta Sarayacu se realizó bajo los siguientes criterios: i). Dinamismo de la actividad económica; ii). Accesibilidad; iii). Tamaño de la población; iv). Tráfico fluvial de pasajeros.

La caracterización de estas localidades se ha desarrollado con el levantamiento de información primaria y secundaria, recopilada en el trabajo de campo y gabinete a través de encuestas, entrevistas y consultas bibliográficas.

\section{Cuadro 1. 1. Localidades en el tramo de estudio.}

\begin{tabular}{|r|l|l|}
\hline No. & \multicolumn{1}{|c|}{ Localidades } & Parroquia \\
\hline 1 & Puerto Latasas & Canelos \\
\hline 2 & Chapetón & Canelos \\
\hline 3 & Humupi & Canelos \\
\hline 4 & Chambira & Sarayacu \\
\hline 5 & Pacayacu & Sarayacu \\
\hline 6 & Yatapi & Sarayacu \\
\hline 7 & Balsaplaya & Sarayacu \\
\hline 8 & Sarayacu & Sarayacu \\
\hline
\end{tabular}

Fuente: CETIF - UCE

\subsubsection{Bondades y beneficiarios del estudio}

Las principales bondades del Estudio de Navegabilidad del río Bobonaza se refieren a la exposición de criterios técnicos respecto a la reducción de tiempos de transporte y a la minimización de riesgos en la navegabilidad principalmente. Por otra parte, desde el punto de vista físico, el río Bobonaza constituye un eje de integración e intercambio entre los poblados que se encuentran en las riberas del mismo. De la misma forma, el estudio se basa en el aprovechamiento de las condiciones naturales del río Bobonaza y no en la adaptación de este a los requerimientos de la navegación. Esto conlleva al diseño de estrategias y políticas alternativas de sustentabilidad para el conjunto de recursos naturales y los procesos ecológicos del sector.

Entre las principales bondades del estudio, se tienen los siguientes puntos: 
- Criterios para el ahorro por pérdida de productos perecibles.

- Criterios para el ahorro en tiempo de viaje para los pasajeros.

- Criterios para el ahorro por daños en el casco y hélice al encallar frecuentemente.

Es importante destacar que los beneficios cuantificables y no cuantificables, generados por el presente estudio, por su efecto multiplicador se trasladarán a la economía del sector.

Entre los principales beneficiarios del estudio se presentan:

Cuadro 1. 2 Beneficiarios directos e indirectos del estudio

\begin{tabular}{|c|l|}
\hline \multicolumn{1}{|c|}{ DIRECTOS } & \multicolumn{1}{|c|}{ INDIRECTOS } \\
\hline $\begin{array}{c}\text { Parroquias locales } \\
\text { Canelos }\end{array}$ & ECORAE \\
Locayacu & GADs cantona- \\
Localidades & GADs \\
- Latasas & provinciales \\
- Chapetón & M.T.O.P. \\
- Humupi & Comunidades \\
- Chambira & Entre otros \\
- Pacayacu & \\
- Yatapi & \\
- Balsaplaya & \\
\hline
\end{tabular}

Elaboración: CETIF - UCE

\subsection{Análisis de externalidades en los procesos de integración local y re- gional}

El estudio permitirá de alguna manera integrar y facilitar el desarrollo de los sectores a lo largo del tramo en estudio y los que se encuentran en el área de influencia indirecta. Posibilitará el acceso de una mayor fuerza laboral en el área de influencia, así como otros agentes económicos que potencializarán el desarrollo de la zona. Motivará la mayor concurrencia de agentes productivos y de comercialización hacia los poblados que cuentan con recursos potenciales para la agricultura y turismo que actualmente son poco aprovechados. Motivará importantes flujos migratorios de índole temporal, debido a los lugres eco turísticos con que cuenta el río Bobonaza en su tramo de estudio.

La integración de las diferentes zonas a lo largo del río Bobonaza impulsará el desarrollo comercial, tendrá gran relevancia, preferentemente para los sectores agrícola y turístico, logrando el progreso de los centros poblados, de las respectivas áreas de influencia en uno $u$ otro sector.

\subsection{Alcances del estudio}

Los alcances de los servicios de consultoría prestados permitirán contar con la información necesaria para establecer y priorizar la ejecución de proyectos de mejoramiento, mantenimiento y seguimiento de la vía fluvial Bobonaza entre Puerto Latasas y Sarayacu.

\subsubsection{Trabajos de campo}

Los trabajos de campo se iniciaron con el posicionamiento de puntos de control en los lugares donde se ubican los centros poblados y sitios de interés para la navegación fluvial. Estos puntos BM's se ubicaron con el fin de obtener información georeferenciada de la localización de los malos pasos donde se efectuaron los levantamientos topográficos.

Los Bancos de Marcas (BM's) se instalaron sobre hitos de concreto debidamente mo- 
numentados y en estructuras rígidas de puentes peatonales sobre el río Bobonaza.

\subsubsection{Levantamiento batimétrico de los malos pasos}

El levantamiento batimétrico de cada uno de los malos pasos del río Bobonaza se realizó en 10 secciones transversales cada 20 metros en una longitud de 100 metros aguas arriba y 100 metros aguas abajo, considerando malos pasos a las secciones del río con profundidades menores a 0,60 metros, considerada la mínima profundidad requerida para la navegación fluvial.

\subsubsection{Levantamiento de las riberas del río}

Para el levantamiento de las riberas del cauce del río se utilizaron imágenes satelitales y fotografías aéreas. Este tipo de imágenes permitieron delimitar las riberas del río Bobonaza y analizar los cambios morfológicos experimentados por el río durante el paso de los años. No se dispone de una imagen única por la longitud del área estudiada, por lo que se ha recopilado un mosaico de imágenes de diferentes características.

\subsubsection{Realización de aforos}

El levantamiento de información de campo fue la base para los estudios de hidráulica fluvial, en los cuales se calcularon los caudales, niveles medios y extremos, velocidades de flujo, capacidad de transporte de palizadas, estimación de niveles de inundación, evaluación del comportamiento del río, erosión de riberas, restricciones a la navegación por presencia de malos pasos, entre otros. Todos estos parámetros sirvieron de soporte para analizar las propuestas de mejoramiento de la navegación fluvial.

\subsubsection{Ubicación e identificación de malos pasos}

Con la información del levantamiento batimétrico de las secciones transversales sobre el río Bobonaza, el análisis hidrológico de niveles y el levantamiento topográfico se procedió a determinar las zonas de poca profundidad (menor a 0,60 m), logrando identificar 42 malos pasos.

Las restricciones a la navegación fluvial entre el tramo Puerto Latasas y Sarayacu se presentan exclusivamente en temporadas de estiaje, pues el bajo nivel del agua hace que las embarcaciones encallen sobre las rocas del lecho del río.

\subsubsection{Levantamiento topográfico de malos pasos}

Con el objetivo de conocer el relieve de las riberas y el área en los malos pasos identificados en el levantamiento batimétrico, se procedió a realizar la tipografía de cada uno de los malos pasos. Los datos de la información topográfica como batimétrica se integraron para realizar el análisis detallado de las zonas problema y así poder definir la geometría completa del cauce del río en los malos pasos.

\subsubsection{Evaluación del comportamiento del cauce}

Los constantes cambios de caudal en el río Bobonaza y la inexistencia de datos históricos respecto al registro de niveles, hizo que sea imposible hacer una aproximación sobre el comportamiento del cauce; sin embargo de acuerdo a información de los habitantes de la zona de influencia y el análisis de datos de campo, se pudo establecer que el cauce del río esta ya definido por lo que el cambio de orientación o di- 
rección es nulo, además la pendiente es muy baja y la velocidad de la corriente no es fuerte; esta aseveración tiene sentido cuando se observa la morfología del río, pues la presencia de los meandros se debe precisamente a características como las descritas en este acápite.

\subsubsection{Evaluación de niveles de inundación}

En vista de que no se encontraron registros de niveles de caudal para el río Bobonaza en ninguna de las estaciones hidrométricas de la provincia de Pastaza, se procedió a indagar esta información a los habitantes de las comunidades involucradas en el trayecto de estudio, encontrándose que los niveles de agua del río Bobonaza tienen una evolución histórica aleatoria, lo que significa que no hay ninguna tendencia sistemática de aumento o reducción de los niveles y en consecuencia de los caudales fluviales. Se conoció también que las variaciones máximas aumentan de manera irregular, por lo que la variación de los niveles máximos y mínimos también son aleatorios en el tiempo y que no siempre se presentan en los mismos años o meses.

Los niveles que se manejan de acuerdo a la información proporcionada por los habitantes son: en crecientes normales el nivel del río aumenta de 1,0 a 2,0 metros, y en máxima creciente el nivel del río aumenta de 3,0 a 4,0 metros, teniendo como nivel histórico 6,0 metros, disminuyendo ese nivel hasta lo normal en 3 días, si se mantienen precipitaciones pluviométricas bajas.

La deforestación descontrolada río arriba -según los moradores- es una de las causas principales por la que el río presenta disminución de caudal cada año, afectando gravemente los niveles de agua en el río Bobonaza, especialmente para el futuro.

\subsubsection{Aspectos socio económicos}

\subsubsection{Densidad poblacional}

En la región amazónica y más aún en las parroquias que integran el área de influencia del estudio la densidad poblacional es relativamente baja, existen pocos habitantes en comparación con la extensión del territorio entre la parroquia de Canelos y Sarayacu. Canelos posee una densidad poblacional de 5,16 habitantes por $\mathrm{km}^{2}$, mientras que en Sarayacu existen 0,94 habitantes por $\mathrm{km}^{2}$ siendo la que menor densidad poblacional presenta.

\subsubsection{Crecimiento poblacional}

Tomando como referencia a las estadísticas del INEC según los diferentes censos que se han llevado a cabo en los últimos 20 años, se estima que el crecimiento poblacional desde 1990 al año 2012 es del $55,23 \%$ para la parroquia de Canelos, mientras que se evidencia un crecimiento poblacional del $29,45 \%$ para la parroquia de Sarayacu. Asimismo, las estimaciones estadísticas reflejan que existe un crecimiento promedio anual para el período 1990-2012 en la parroquia de Canelos y Sarayacu del $2,23 \%$ y $1,24 \%$ respectivamente.

\section{5.9.3 Tipo de vivienda}

El tipo de vivienda más sobresaliente en la zona de influencia del presente estudio es la Choza, considerando aquella construcción que posee paredes de madera, techo de paja y piso de tierra, categoría común en la región, los materiales utilizados para la construcción de este tipo de viviendas son extraídos de la misma zona. El tipo de vivienda Choza representa el 36,36\% para 
Canelos y el $61,07 \%$ para Sarayacu de un total de 462 y 461 respectivamente.

\subsubsection{Fuente principal de aprovisiona- miento de agua}

El agua es conseguida por los hogares de Canelos y Sarayacu principalmente de ríos y vertientes, siendo el $44,16 \%$ y $54,96 \%$ respectivamente. Del total de viviendas investigadas, el 49,55\% posee como fuente de aprovisionamiento del líquido vital los ríos y vertientes. El agua que es conseguida de estas fuentes pasa a ser encaminada por efectos de gravedad y por medio de mangueras hasta las viviendas de las familias. Esta misma agua es utilizada para beber, cocinar, y usos del hogar en general; asimismo el agua para beber es utilizada directamente de la fuente de aprovisionamiento sin recibir algún tipo de purificación.

\subsubsection{Estructura de la población por edad}

La mayor población en las parroquias de Canelos y Sarayacu oscila entre los 0 y 19 años de edad; es decir la mayoría son niños y jóvenes. En el grupo de edad de 5 a 9 años se ubica el 16,34\%, en el grupo de 10 a 14 años se ubica el 15,20\%, en el grupo menores de 5 años esta el 13,64\% y en el grupo de 15 a 19 años esta el 12,41\% del total de la población en estas parroquias, totalizando 4.891 habitantes para el año 2012.

\subsubsection{Población en el área de influencia}

Con los datos de población según los censos del INEC para los años 1990, 2001 y 2010 se realizó la determinación de la tasa de crecimiento poblacional promedio entre períodos y con estas tasas resultantes se saco una tasa de crecimiento poblacional promedio global y se proyecto para dos años, tomando como último año de censo el año 2010.

\section{Cuadro 1. 3 Número de habitantes por parroquia}

\begin{tabular}{|l|l|r|r|}
\hline PARROQUIA & \multicolumn{1}{|c|}{ FREQ } & \multicolumn{1}{c|}{$\%$} & \multicolumn{1}{c|}{ CUM } \\
\hline CANELOS & 2.271 & 46,43 & 46,43 \\
\hline SARAYACU & 2.620 & 53,57 & 100,00 \\
\hline TOTAL & $\mathbf{4 . 8 9 1}$ & $\mathbf{1 0 0 , 0 0}$ & \\
\hline
\end{tabular}

Fuente: Encuesta a hogares "Proyecto Navegabilidad río “Bobonaza”, 2012.

Elaboración: CETIF - UCE

\section{1-5.9.7 Descomposición de la población}

La población en edad de trabajar PET, representa el $67,17 \%$ de la población total, mientras que la población económicamente activa PEA, que es parte de la PET es el $40,17 \%$ y asimismo la población económicamente inactiva PEI que igualmente es parte de la PET, representa el $27,01 \%$ de la población total.

También se revela que el $29,98 \%$ de la población corresponde a menores de 10 años, como se indico anteriormente en estos grupos de edad existe concentración de la población y el 2,85\% corresponde a la población mayor de 65 años.

\subsubsection{Nivel de empleo y desempleo}

El nivel de empleo en las parroquias de Canelos y Sarayacu es del $44,85 \%$ y $43,03 \%$ respectivamente. El nivel de desempleo para estas mismas parroquias es del $55,15 \%$ y $56,97 \%$ respectivamente. Entre las dos parroquias poseen un nivel de em- 
pleo del $43,85 \%$ y el desempleo se ubica en el 56,15\%; es decir que más de la mitad de la PEA se encuentra desempleada, no posee una fuente de ingreso laboral.

\subsubsection{Estructura de la población por na- cionalidad}

Teniendo en cuenta que la zona de estudio involucra dos parroquias por estar contiguas al río Bobonaza se establecen características diferenciadas, ya que en Canelos existe presencia de dos razas bien definidas, la mestiza y la indígena. En Sarayacu la situación es diferente ya que la mayoría de los habitantes son indígenas.

La nacionalidad de mayor representación es la kichwa con el $97,96 \%$ del total de las personas investigadas en la zona de estudio, esta nacionalidad es común en las dos parroquias.

\subsubsection{Rama de actividad económica}

La rama de actividad de mayor incidencia tanto en la parroquia de Canelos como en la de Sarayacu es el cultivo de productos agrícolas y cría de animales, esta actividad es a la que se dedica el $62,14 \%$ de las personas, seguida de la rama otras, con el $26,10 \%$ que básicamente se involucran el cultivo de fibra para la construcción de techos de las viviendas y artesanías hechas de este material, así como las diligencias realizadas por ciertos dirigentes políticos del sistema de gobierno indígena que se constituye especialmente en la parroquia de Sarayacu.

\subsubsection{Nivel de ingreso}

El nivel de ingreso para la población de la zona de influencia se encuentra en un promedio mensual de US\$60,10. El pro- medio mensual para el caso de la parroquia de Canelos es de US\$ 63,21, aquí el ingreso es más alto que el nivel de ingreso global porque en esta parroquia existe mayor vinculación con fuentes de empleo generadoras de ingreso. En la parroquia de Sarayacu, el promedio mensual se encuentra en US\$ 57,17 valor más bajo que el obtenido en Canelos y a nivel global. Este indicador evidencia la escasa participación de la población en actividades económicas que generen principalmente un ingreso laboral.

\subsubsection{Nivel de escolaridad}

Para el caso de Canelos, la escolaridad promedio de la población es de 5,76 años de estudios, que corresponde al nivel de primaria; mientras que en la parroquia de Sarayacu, este índice es de 6,54 años de estudios, valor que corresponde igualmente al nivel de primaria. A nivel general, el nivel promedio de escolaridad de la población en la zona de influencia es de 6,19 años de estudios.

\subsubsection{Niveles de pobreza}

La mayor concentración de población de las parroquias Canelos y Sarayacu está bajo la línea de pobreza, representando el 97,57\%; mientras que una mínima parte de la población se encuentra por encima de la línea de pobreza, representando el 2,43\%. El ingreso per cápita percibido por las personas no permite cubrir el consumo calórico siquiera del establecido en la línea de pobreza US\$ 76,35; es decir que las personas no cubren sus necesidades básicas de consumo con el ingreso que obtienen actualmente. 


\subsubsection{Conocimientos ancestrales}

Los conocimientos ancestrales de las comunidades kichwas, asentadas a orillas del río Bobonaza, son múltiples y variados. Practican dos idiomas. Poseen un sistema de gobierno comunitario. Hacen vasijas de barro sin hornos de cocción. Curan sus dolencias físicas y espirituales con infusiones de plantas, hierbas y rocas del río. Acuden a los shamanes, depositarios de la cultura ancestral, cuando ya la medicina occidental ha cumplido su rol. Es común el verlos teñidos el cabello, que tanto hombres como mujeres lo lucen largo. No hay obesos en dichas comunidades. Utilizan fertilizantes naturales, entre otros.

\subsubsection{Aspectos ambientales}

\subsubsection{Caracterización del clima}

El clima de la zona de influencia es mega térmico lluvioso, que se caracteriza por recibir una precipitación de entre 3.000 y $4.000 \mathrm{~mm}$ casi todo el tiempo, a excepción de otros sitios con variaciones de precipitaciones menores, entre 2.500 a 3.000 $\mathrm{mm}$.

\subsubsection{Caracterización del suelo}

Los suelos presentes en el área de influencia son aluviales, entisoles, histosoles e inceptisoles. Los suelos aluviales se encuentran a las orillas del río Bobonaza y se forman principalmente de sedimentos de tipo arcillosos. Los suelos Entisoles son poco desarrollados o evolucionados, tienen un epipedonocrílico (amarillento), y son suelos originarios de cangagua pura erosionada. Los suelos Histosoles son suelos orgánicos con más del $20 \%$ de materia orgánica. Los suelos Inceptisoles tienen como característica principal el incipiente desarrollo del suelo, ya que son considerados suelos inmaduros en su evolución, se han originado a partir de materiales resistentes o ceniza volcánica. Son suelos de textura limosa, franco-limosos, francoarcilloso-limoso de poca profundidad, con un pH ligeramente ácido.

\subsubsection{Caracterización del agua}

Los resultados de análisis físico-químicos demuestran que no existe contaminación alguna del agua en al área de estudio, desde puerto Latasas hasta Sarayacu. En los que respecta a los resultados tipo biológico detallados hay un margen de contaminación de coliformes fecales que marca un valor de $2.500,00 \mathrm{NMP} / 100 \mathrm{ml}$ sobrevalorando al máximo del TULAS de 200,00 NMP/100ml. En relación al resto de los parámetros no hay ningún grado de contaminación.

\subsubsection{Caracterización del aire}

De las emisiones generadas por el transporte fluvial, el $90 \%$ corresponde al $\mathrm{CO}_{2}$ por lo que cabe mencionar que las emisiones de $\mathrm{CH}_{4}$ y $\mathrm{N}_{2} \mathrm{O}$ no son significativas. De acuerdo a la Convención de las Naciones Unidas sobre el Cambio Climático y el Inventarío de la Naciones Unidas 1990-2002, se estima que por cada litro de combustible consumido en procesos de combustión interna a gasolina se generan 2,3035 kg de $\mathrm{CO}_{2}$. Los datos, análisis y estimaciones de resultados servirán como patrón para poder identificar generaciones totales de dióxido de carbono, que dependerán de la frecuencia de viajes y rutas que se realizarán en el área del proyecto. 


\subsubsection{Caracterización del ruido}

Se estima un promedio general de ruido de $61,95 \mathrm{~dB}$ en toda el área del proyecto. En los diferentes embarcaderos de las comunidades se encuentra valoraciones promedios de $56,85 \mathrm{~dB}$ cuando los motores de los botes están apagados. Cuando estos se encuentran encendido generan $73,00 \mathrm{~dB}$ y dentro del bote cuando la gente se traslada a diferentes sitios (A bordo) se producen valores de 79,74 dB. Cerca de las orillas, fuera de borda y con los motores encendidos los dB generados por las canoas motorizadas son de 48,60 como promedio.

Las pistas, es el área donde se produce mayor cantidad de ruido con una valoración total de 103,50 dB, considerado como dañino para el oído humano según el Texto Unificado de Legislación Ambiental Secundaria TULAS.

\subsubsection{Evaluación de impactos ambien- tales}

El área de estudio no presenta altos grados de contaminación actualmente, sino que se van a presentar con más intensidad en la etapa de ejecución del proyecto, etapa que se va a ejecutar de forma temporal, por un mediano plazo, y al finalizar las diferentes alternativas del proyecto todo volverá a su normalidad. Para la verificación de posibles impactos a largo plazo, debido a la implementación de nueva infraestructura y nuevas alternativas, se monitoreará factores ambientales de agua y aire expuesto en el Plan de Manejo Ambiental del presente estudio, al finalizar la ejecución del proyecto.

La construcción de pequeños embarcaderos en las localidades de Puerto Latasas, Chapetón, Pacayacu y Sarayacu, causarán impactos mínimos y en áreas pequeñas, por lo que se recomienda su aplicación por ser un bien y servicio de cobertura social.

\subsection{Propuestas y plan de inversiones}

En el tramo del río Bobonaza estudiado, las principales restricciones a la navegación existentes son:

- Presencia de malos pasos identificados en 42 sitios.

- Meandros muy cerrados.

- Variación aleatoria de caudales.

- Inexistencia de infraestructuras adecuadas para dar facilidad de embarque y desembarque.

- Inexistencia de estaciones hidrométricas para registro de niveles.

- Inexistencia de embarcaciones que brinden un transporte seguro y eficiente.

\subsubsection{Alternativas para el mejora-} miento de la navegabilidad del río Bobonaza

\subsubsection{Inversión en infraestructura fí- sica}

Como alternativas de solución e inversión en infraestructura física y actividades conexas para mejorar la navegabilidad del río Bobonaza y superar los malos pasos se presentan las siguientes opciones:

- Obras para superar malos pasos.

Alternativa A: Estructuras longitudinales.

Alternativa B: Sistema de espigones.

Alternativa C: Limpieza mecánica.

Alternativa D: Programa de mingas comunitarias.

Alternativa E: Limpieza de palizadas. 
- Obras para facilidades de atraque Alternativa F: Construcción de embarcaderos.

\subsubsection{Descripción de alternativas}

\section{OBRAS PARA SUPERAR MALOS PASOS}

\section{Alternativa A: Estructuras longitudinales}

Una de las formas más eficientes para controlar el cauce del río en las zonas de los malos pasos, es la construcción de muros longitudinales (enrocado) a lo largo de la corriente, siguiendo los patrones de curvatura típicos de la corriente. Estos muros pueden construirse dentro del cauce disminuyendo la sección para facilitar la navegación y también servirán como medidas de protección para evitar márgenes erosionadas o socavadas. El tiempo de ejecución de la obra es de 5 días por unidad de enrocado con una inversión de US\$ 1.754,95 por estructura.

\section{Alternativa B: Sistema de espigones}

Entre las ventajas que presenta este tipo de infraestructura, se pueden mencionar: facilidad constructiva, bajo costo, facilidad de reparación, posibilidad de usar materiales de la zona, usar la mano de obra local, no se requiere mano de obra altamente especializada, entre otras. Existe una muy variada gama en diseño de espigones, pero las estructuras recomendadas para el encauzamiento del río Bobonaza en las zonas de malos pasos, dadas sus características hidráulicas, constituyen los espigones permeables que se usan cuando se trata de un río navegable y en el que se trata de mantener una sección hidráulica central con un determinado calado, que facilita la navegación fluvial.
Esta alternativa consiste en la construcción de un espigón en 19 malos pasos de los 42 identificados y estudiados en el trabajo presente. La ubicación de estas estructuras depende de las características de cada mal paso y se ubicarán a la margen derecha o izquierda del río, según el caso. Los materiales utilizados para la construcción son las mismas rocas del río cubiertas por malla metálica de celdas hexagonales de triple torsión. La mano de obra se recomienda que sea local como mecanismo de inclusión y participación comunitaria. El tiempo de duración en la construcción de la obra es de 20 días por espigón, representando una inversión de US\$ 4.048,54 por espigón.

\section{Alternativa C: Limpieza mecánica}

Esta alternativa consiste en la limpieza mecánica del canal de navegación, específicamente en los 42 puntos considerados malos pasos. Esta alternativa permite extraer el material pétreo del lecho del río para ser reubicado en otro lugar; ya sea en el propio lecho del río o en sus márgenes.

Los costos se determinaron de acuerdo a una jornada diaria de trabajo de 8 horas hábiles, el costo total de ésta actividad está dado por el número de días laborados (referencial 42 días) para la eliminación de todos los malos pasos en donde se pueda aplicar esta alternativa, ya que la accesibilidad para la retroexcavadora es muy difícil. Esta alternativa representa una inversión de US\$ 1.250,00 por día.

\section{Alternativa D: Programa de mingas comu- nitarias}

La organización y unión comunitaria es una de los mecanismos fundamentales para alcanzar el desarrollo y transformación de las comunidades rurales, pues promueven 
el fortalecimiento de los individuos y grupos para lograr por sí mismos transformaciones positivas que mejoren el acceso a diferentes productos y servicios, mejorando de este modo su calidad de vida. Esta alternativa consiste en organizar programas de mingas comunitarias para realizar actividades de limpieza del cauce del río Bobonaza, especialmente donde se identificaron los 42 malos pasos. Se propone proporcionar herramientas, alimentación y un incentivo económico por día de trabajo. Esta alternativa representa una inversión de US\$ 750,00 por día de trabajo comunitario.

\section{Alternativa E: Limpieza de palizadas}

Teniendo en cuenta el peligro que representan las palizadas para la navegación se ha propuesto un programa para limpieza de palizadas de dos veces por año. Este programa consiste en implementar motosierras y personal capacitado en embarcaciones que patrullen una zona asignada de responsabilidad.

El trabajo de las embarcaciones consistirá en interceptar los troncos flotantes, adecuarlos para subirlos a bordo y transportarlos a las orillas, y mediante el uso de motosierras, trozarlos de modo que puedan ser utilizados por la población como leña u otro fin. Los períodos de patrullaje serían entre los meses de abril y junio, que es donde el problema de las palizadas se presenta con mayor intensidad. Esta alternativa representa una inversión de US\$ $51.000,00$ por año.

\section{OBRAS PARA FACILIDADES DE ATRAQUE}

\section{Alternativa F: Construcción de embarca- deros}

De acuerdo a los estudios realizados es muy riesgoso emplear infraestructura portuaria rígida en el río Bobonaza debido a la dinámica de flujo, ya que se ha determinado que es muy inestable especialmente cuando se presenta épocas de intensas precipitaciones. Por tanto se propone un tipo de embarcadero básico que constará de las siguientes estructuras:

Caseta de Espera; y, Rampa de Acceso con pasamanos de madera.

Esta propuesta consiste en la construcción de 4 embarcaderos al servicio del transporte fluvial. Las estructuras serán ubicadas en áreas próximas a las comunidades de mayor concentración de habitantes por su incidencia en la generación o atracción de viajes: Puerto Latasas, Chapetón, Pacayacu y Sarayacu. El tipo de construcción por cada embarcadero es de 7 días con una inversión de US\$ 3.256,50 por infraestructura.

\subsubsection{Inversión en equipos y maqui- narias}

La determinación de los niveles de agua en los ríos amazónicos, resulta una herramienta importante para estudios hidrológicos del sistema fluvial de la región, sin embargo en la actualidad y especialmente en el área de influencia del estudio, no se cuenta con ningún tipo de información limnimétrica.

La regla limnimétrica es el instrumento que permite obtener datos del nivel de agua durante un programa observacional sistemático. El instrumento de medición directa es el limnímetro. Los datos de nivel de agua se utilizan como base para computar registros de caudal o cambios en el almacenamiento de agua. 
La instalación de reglas limnimétricas para el caso del río Bobonaza, son importantes para la navegación y alerta de inundaciones.

En este sentido se plantea una propuesta para la instalación de por lo menos 5 reglas limnimétricas en el área de influencia, específicamente en las localidades de Puerto Latasas, Chapetón, Humupi, Pacayacu y Sarayacu, alternativa que representa una inversión de US\$2.830,00.

\subsubsection{Inversión en ayudas a la nave- gación}

Para el caso del río Bobonaza, donde el transporte fluvial se realiza en horas del día y donde no existe fuentes de energía artificial, se recomienda la señalización vertical e inclusión de iconografía en una carta electrónica del tramo del río entre Puerto Latasas y Sarayacu, la misma que permitirá a los navegantes tener a disposición toda la información concerniente a curvas de nivel, canal navegable, comunidades, ubicación de malos pasos, ubicación de embarcaderos, reglas limnimétricas, entre otras.

La función de las señales verticales fluviales es indicar a los usuarios de la vía fluvial, las precauciones que deben tener en cuenta, las limitaciones que presenta el canal navegable o tramos del río por donde deben navegar. La correcta señalización preventiva informará de qué modo se deberá transitar por el río Bobonaza.

Para lograr una adecuada visibilidad, las señales verticales estarán constituidas de pinturas reflexivas con revestimientos anticorrosivos. Las dimensiones recomendables para estos rótulos son de $2 \times 1 \mathrm{~m}$ fija, debido a su altura tienen una observación visual de gran alcance. La ubicación de las señalizaciones se hará con especial énfasis en los 42 malos pasos identificados. De acuerdo a la determinación de los malos pasos, infraestructura física a implementarse, equipos, comunidades, entre otros, se ha estimado un total de 59 paneles de señalización vertical, con una repetición de 3 paneles como función preventiva por cada panel, representando una inversión de US\$ 475,00 por cada señal vertical.

\subsubsection{Inversión en medios de trans- porte fluvial}

De acuerdo al análisis de oferta y demanda de transporte fluvial y luego de haber navegado, analizado el transporte de pasajeros in situ, cuerpos de agua y caudales presentes en la zona de estudio, se ha diseñado una embarcación TIPO que brinde el servicio de transporte de forma segura en el río Bobonaza, la embarcación es del tipo casco Aluminio Naval con fondo plano reforzado y según las características críticas que presenta el río en la temporada de estiaje que son 7,0 $\mathrm{m}$ de espejo efectivo y $0,25 \mathrm{~m}$ de calado. La simulación efectuada indica que la embarcación navegará en óptimas condiciones y sin problemas a la velocidad de $20 \mathrm{~km} /$ hora pudiendo alcanzar velocidades de hasta $30 \mathrm{~km} / \mathrm{h}$. El casco diseñado es muy estable hasta los $0,40 \mathrm{~m}$ de calado pero a bajas velocidades. La eficiencia ganada por la embarcación en resistencia al avance es favorable, pudiendo trabajar con motores fuera de borda pata corta de 25 HP o 40 HP. La embarcación es muy estable en los calados de 0,25 a 0,40 metros.

Se establece que debe existir una línea regular de transporte fluvial que cumpla el itinerario Latasas - Sarayacu - Latasas, con una frecuencia de viaje de dos veces por mes con una flota total de 5 embarcacio- 
nes tipo. El valor de la inversión es de US\$ 21.000 por embarcación.

\subsubsection{Inversión en transferencia de tecnología y capacitación}

La transferencia de tecnología, fuerza básica del desarrollo, está ligada inseparablemente a la inversión en capital humano y a los recursos naturales. Por lo tanto la tecnología y transferencia del conocimiento deben ser condición sine qua non para el mantenimiento de la navegabilidad del río Bobonaza, considerando la sensibilidad de los recursos naturales de la zona, pues lo que generalmente a sucedido en la región Amazónica es que, esta transferencia de tecnología es limitada y no se ha adaptado a la cultura, necesidades y posibilidades de la población local.

El objetivo de este programa de inversión es desarrollar medidas significativas y eficaces para fomentar y facilitar la transferencia de tecnologías y el acceso a las mismas, por parte de las personas que conforman el área de influencia del estudio. La ejecución del programa contribuirá también al mantenimiento de la navegabilidad del río, seguridad del transporte y gestión logística de viaje, se toma en consideración circunstancias particulares y factores limitativos de las comunidades, tales como aislamiento y vulnerabilidad dadas sus características culturales. La ejecución de esta propuesta está basada en cuatro propósitos que forjan la transferencia de tecnología y capacitación como un proceso escalonado y de largo plazo, significando un programa de proyectos con una duración de 6 años y una inversión de US\$ $8.303 .625,00$

\subsubsection{Inversión en monitoreo y seguimien- to ambiental}

Se plantea un Plan de Manejo Ambiental que se centra en especificar las acciones o medidas que deberá tomar en cuenta la empresa constructora y el operador de proyecto para la prevención, control, mitigación y compensación ambiental en procura de un desarrollo sustentable de las actividades desarrolladas en el río Bobonaza y sus alrededores. A pesar de que no todas las acciones del proyecto generan impactos negativos sobre los elementos ambientales considerados, el Plan de Manejo Ambiental introducirá medidas tendientes a evitar que el medio ambiente, la población que se asienta en su área de influencia y el personal que trabaja en la construcción y operación del proyecto se vean afectados. La inversión para esta propuesta es de US\$34.543,94.

\subsubsection{Inversión en alternativas de desarro- Ilo local}

Se plantea una propuesta de desarrollo local, entendiendo al mismo como una estrategia que involucra a diferentes actores sociales públicos - privados, a su cultura y a los recursos locales disponibles en las parroquias de Canelos y Sarayacu, en la búsqueda de soluciones y en el diseño de un proyecto colectivo que permita mejorar su calidad de vida. Se determinó cuatro alternativas en función de las necesidades identificadas en la zona de influencia del presente estudio, siendo el sistema productivo, sistema turístico, sistema de servicios públicos y sistema de servicios de transporte. Propuestas que tienen un tiempo de ejecución en conjunto de 8 años, con una inversión de US\$ $8.862 .480,00$. 


\subsection{Programa de trabajo}

El programa de trabajo desarrollado para la elaboración del Estudio de Navegabilidad del río Bobonaza comprendido entre el tramo Canelos (Puerto Latasas) hasta Sarayacu tiene por objetivo detallar de forma pormenorizada el plan y cronograma de actividades a realizar.

\subsubsection{Actividades preliminares}

Las actividades preliminares desarrolladas para el estudio fueron las siguientes:

- Firma del Contrato el 19 de noviembre de 2012.

- Adelanto del 70\% el 26 de noviembre de 2012

\subsubsection{Actividades de Inicio}

- Recopilación y revisión de la información existente.

- Reconocimiento de campo.

- Organización de los grupos de trabajo para recopilar información en el campo

- Preparación de equipos, herramientas de estudio, software, material de apoyo, etc.

- Plan de trabajo por área de estudio.

\subsubsection{Estudios básicos}

Dentro de estos estudios estuvieron las siguientes actividades:

- Levantamiento topográfico, posicionamiento de puntos de control BMs, levantamiento topográfico en las áreas de probable ubicación de embarcaderos y malos pasos más relevantes, procesamiento de in- formación, elaboración y edición de planos.

- Levantamiento batimétrico, en los sitios probables de ubicación de embarcaderos y en todos los mal pasos a lo largo del tramo en estudio.

- Hidrología, determinación de las estaciones meteorológicas e hidrológicas que ofrezcan información que pueda ser utilizada para la evaluación hidrológica de la cuenca del río Bobonaza.

- Levantamiento de información socio económica, ambiental, socio antropológica, mediante el uso de encuestas y entrevistas.

\subsubsection{Hidráulica fluvial}

Las actividades de hidráulica fluvial que fueron consideradas en este estudio fueron:

- Recopilación de datos complementarios del sistema hidrológico de la cuenca del río Bobonaza

- Evaluación hidrológica del río Bobonaza, en el tramo Canelos - Sarayacu.

- Evaluación del comportamiento del cauce del río Bobonaza, tramo $\mathrm{Ca}$ nelos-Sarayacu, los cambios que en él se producen (meandros, trenzas, cambios en el cauce, talweg y su tendencia de comportamiento futuro.

- Identificación de malos pasos, características, alternativas de solución.

- Estimación de los niveles de inundación.

- Valores de medición de caudales.

- Erosión de riberas. 
- Estimación del transporte de palizadas.

- Elaboración del informe final.

\subsubsection{Estudio de navegabilidad y trans- porte fluvial}

Para los estudios de navegabilidad y transporte fluvial fueron considerados las siguientes actividades:

- Fase inicial de identificación, determinación de la configuración del cauce mediante el procesamiento de información digital existente.

- Identificación de zonas de acopio de carga fluvial y pasajeros.

- Identificación de probables sitios para la ubicación de embarcaderos.

- Caracterización de embarcaciones e infraestructura fluvial existente $y$ carga que se transporta a través del río Bobonaza en el tramo de estudio.

- Determinación de la probable ubicación de escalas limnimétricas para medir los niveles del río.

- Determinación de la ubicación de BMs.

- Realizar mediciones batimétricas en los tramos del río donde serán considerados para la instalación de muelles fluviales o embarcaderos y malos pasos más relevantes.

\subsubsection{Estudio socio económico}

Para desarrollar el estudio socio económico se planificó:

- Recolección de información mediante encuestas, para lo cual, el equipo técnico responsable del es- tudio socioeconómico se dividió en dos frentes de trabajo:

\section{Detalle frente de trabajo, Equipo 1:}

Parroquia: Sarayacu

Levantamiento de campo: Desde localidad de Pacayacu hasta Sarayacu

Número de encuestas: 131 hogares

Días disponibles: 5

Detalle frente de trabajo, Equipo 2:

Parroquia: Canelos

Levantamiento de campo: Desde Canelos hasta poblados contiguos a Pacayacu.

Número de encuestas: 77 hogares

Días disponibles: 5

\section{Taller técnicas de grupo:}

Lugar: Sarayacu

Asistentes número referencial: Más de 30 personas.

Días disponibles: 1

Las actividades realizadas en este campo fueron:

- Procesamiento de la información recolectada en campo.

- Análisis demográfico del área de estudio.

- Niveles de educación, condiciones de vivienda, actividades productivas, niveles de pobreza, condiciones de empleo, estructura de la población por edad, estructura de la población por nacionalidad, condiciones de servicios básicos, etc.

- Elaboración el informe parcial.

- Análisis del transporte.

- Oferta y Demanda de transporte.

- Análisis de actores. 
- Solución de conflictos.

- Estadísticas de proyecciones y tráfico.

- Proyecciones de la demanda de tráfico.

- Demás aspectos socio-económicos.

- Elaboración y correcciones del informe final.

\subsubsection{Estudio ambiental}

Las actividades del estudio ambiental comprendieron:

Etapa inicial, recopilación de información identificando condiciones actuales ambientales basándose en una recopilación bibliográfica y trabajo de campo junto con un análisis visual del área.

Salida de campo, elaboración de la Línea Base Ambiental mediante encuestas.

Ubicación e identificación de factores ambientales para la recolección de datos en el trabajo de campo en el área directa. Identificación e implementación de una metodología para el Levantamiento de Línea Base de factores de suelo, aire, agua, flora y fauna.

Descripción y caracterización del medio físico, identificación de las condiciones actuales del área de influencia.

Evaluación ambiental preliminar, identificación de impactos, identificación de impacto en el medio socioeconómico y cultural.

Etapa final, procesamiento de la información, presentación de informes parciales, plan de trabajo ambiental, presentación de informe final.

\subsubsection{Estudio sociológico / antropológico}

Las actividades de sociología y antropología para este estudio comprendieron:

- Apoyar en la realización de encuestas socio económicas.

- Mediante la observación participativa tener una visión holística de las características socio antropológicas.

- Recabar información primaria y secundaria de las principales características socio antropológicas de la zona de influencia.

\subsubsection{Plan de inversiones}

El plan de inversiones del presente estudio comprende los siguientes aspectos:

- Sincronización de información.

- Inversión en transferencia de tecnología, infraestructura física, capacitación, equipos y maquinarias, ayudas a la navegación, medios de transporte fluvial de carga y pasajeros, actividades de seguimiento y control.

\subsubsection{Actividades adicionales}

Las actividades adicionales contempladas para el estudio son:

- Diseño del plano de formas de una embarcación tipo, tomando en consideración las características propias del río Bobonaza.

- Propuestas de inversión para desarrollo local. 


\subsubsection{Actividades totales}

Las actividades totales que se desarrollaron para la elaboración de este estudio fueron:

- Trabajos de campo.

- Trabajos de gabinete.

- Elaboración y presentación del primer informe.

- Elaboración y presentación del segundo informe.

- Elaboración y presentación del informe final.

\subsubsection{Personal participante en el estudio}

\section{Cuadro 1. 4 Personal de técnicos en el} estudio

\begin{tabular}{|c|c|c|}
\hline No & ESPECIALIDAD & $\begin{array}{c}\text { NOMBRES Y APELLI- } \\
\text { DOS }\end{array}$ \\
\hline 01 & Jefe de Proyecto & $\begin{array}{l}\text { Ing. Salomón JAYA Que- } \\
\text { zada }\end{array}$ \\
\hline 02 & $\begin{array}{l}\text { Esp. en Hidráuli- } \\
\text { ca Fluvial }\end{array}$ & $\begin{array}{l}\text { Ing. Jaime GUTIÉRREZ } \\
\text { Padilla }\end{array}$ \\
\hline 03 & $\begin{array}{l}\text { Esp. en Ingenie- } \\
\text { ría Naval }\end{array}$ & $\begin{array}{l}\text { Ing. José RODRÍGUEZ } \\
\text { Lamchang }\end{array}$ \\
\hline 04 & $\begin{array}{l}\text { Esp. en Topogra- } \\
\text { fía }\end{array}$ & $\begin{array}{l}\text { Ing. Mónica CORONEL } \\
\text { Silva }\end{array}$ \\
\hline 05 & $\begin{array}{l}\text { Esp. en Econo- } \\
\text { mía de Transpor- } \\
\text { te }\end{array}$ & Ec. Jhon USIÑA Pinchao \\
\hline 06 & $\begin{array}{l}\text { Esp. en Socio } \\
\text { economía }\end{array}$ & $\begin{array}{l}\text { Ec. Argenis HEREDIA } \\
\text { Campaña }\end{array}$ \\
\hline
\end{tabular}

\begin{tabular}{|c|l|l|}
\hline 07 & $\begin{array}{l}\text { Esp. en Sociolo- } \\
\text { gía }\end{array}$ & $\begin{array}{l}\text { Soc. Edwin VELASCO } \\
\text { Atahualpa }\end{array}$ \\
\hline 08 & $\begin{array}{l}\text { Esp. en Medio } \\
\text { Ambiente }\end{array}$ & $\begin{array}{l}\text { Ing. Edy GAONA Luzuria- } \\
\text { ga }\end{array}$ \\
\hline
\end{tabular}

Elaboración: CETIF - UCE

\subsection{Conclusiones}

- Los problemas relativos a la morfología fluvial constituyen un reto permanente para la ingeniería; la comprensión de las variadas formas que adoptan los ríos es indispensable para el diseño de las obras que estén en contacto con el río o cerca de él. Los ríos aluviales toman su nombre precisamente del hecho de correr sobre un material aluvial, que es el que ha sido transportado y depositado por el río.

- El levantamiento batimétrico de los 42 malos pasos del río Bobonaza se realizó en 10 secciones transversales cada 20 metros en una longitud de 100 metros aguas arriba y 100 metros aguas abajo, considerando malos pasos a las secciones del río con profundidades menores a 0,60 metros, considerada la mínima profundidad requerida para la navegación fluvial.

- En vista de que no se encontraron registros de niveles de caudal para el río Bobonaza en ninguna de las estaciones hidrométricas de la provincia de Pastaza, se procedió a indagar esta información a los habitantes de las comunidades involucradas en el trayecto de estudio, 
encontrándose que los niveles de agua del río Bobonaza tienen una evolución histórica aleatoria, lo que significa que no hay ninguna tendencia sistemática de aumento o reducción de los niveles y en consecuencia de los caudales fluviales. Las variaciones máximas aumentan de manera irregular, por lo que la variación de los niveles máximos y mínimos también son aleatorios en el tiempo y no siempre se presentan en los mismos años o meses.

- Las riberas de los meandros del río Bobonaza en algunos tramos están expuestas a procesos de erosión lateral causada por el desplazamiento de agua sinuoso, lo que experimenta una variación en el curso normal de sus aguas y tienden a emigrar depositando su carga, originando diferentes formas de acumulación como playas y terrazas o a veces desbordándose y sedimentando materiales finos en las depresiones del terreno o zonas bajas, lo que da lugar a la formación de extensas áreas de malos pasos.

- El área de influencia para el Estudio de Navegabilidad del río Bobonaza desde Canelos (Puerto Latasas) hasta Sarayacu - primera etapa, se ha definido como el espacio geoeconómico de origen/destino de pasajeros que se movilizan a través del río Bobonaza en el tramo Puerto Latasas y Sarayacu.

- Tomando como referencia a las estadísticas del INEC según los diferentes censos que se han llevado a cabo en los últimos 20 años, se estima que el crecimiento poblacional desde 1990 al año 2012 es del $55,23 \%$ para la parroquia de Canelos, mientras que se evidencia un crecimiento poblacional del 29,45\% para la parroquia de Sarayacu. Asimismo, las estimaciones estadísticas reflejan que existe un crecimiento promedio anual para el período 1990.

- El nivel de ingreso para la población de la zona de influencia se encuentra en un promedio mensual de US\$ 60,10. El promedio mensual para el caso de la parroquia de Canelos es de US\$ 63,21, aquí el ingreso es más alto que el nivel de ingreso global porque en esta parroquia existe mayor vinculación con fuentes de empleo generadoras de ingreso. En la parroquia de Sarayacu, el promedio mensual se encuentra en US\$ 57,17 valor más bajo que el obtenido en Canelos y a nivel global. Este indicador evidencia la escasa participación de la población en actividades económicas que generen principalmente un ingreso laboral.

- La población en edad de trabajar PET, representa el $67,17 \%$ de la población total, mientras que la población económicamente activa PEA, que es parte de la PET es el $40,17 \%$ y asimismo la población económicamente inactiva PEI que igualmente es parte de la PET, representa el $27,01 \%$ de la población total. Esta PEI corresponde principalmente a personas que se encuentran en condición de estudiantes. 
- En frecuencia de viajes, los orígenes de mayor relevancia constituyen Pacayacu y Sarayacu con un peso relativo del $46,60 \%$ y $41,64 \%$ respectivamente. La localidad de mayor atracción de viajes es Latasas con el $90,51 \%$ y existe una movilidad interna entre Pacayacu y Sarayacu del 5,83\%, siendo el destino esta última localidad.

- Se plantea la inversión en transferencia de tecnología, infraestructura física, capacitación, equipos y maquinarias, ayudas a la navegación, medios de transporte fluvial de carga y pasajeros, actividades de seguimiento y control ambiental.

\subsection{Recomendaciones}

El equipo consultor comprometido con la comunidad, puntualiza las recomendaciones realizadas por miembros de las diferentes comunidades indígenas ubicadas entre puerto Latasas y Sarayacu, las mismas que fueron acogidas con beneplácito y expuestas en este acápite:

- Es necesario que el transporte fluvial por el río Bobonaza sea más seguro, se debe obligar el uso de chalecos salvavidas para tripulantes y pasajeros.

- Se recomienda hacer un estudio muy detallado de la contaminación generada por la navegación fluvial, específicamente por combustibles, aceites y desechos sólidos sobre el río Bobonaza.

- Se recomienda que se constituya una compañía de transporte fluvial que cubra la ruta Puerto Latasas - Sarayacu, con una frecuencia de viaje, por lo menos de dos veces por mes, pues en la determinación de la demanda de pasajeros se justifica la creación de una compañía, misma que deberá ser operada por los miembros de la comunidad.

- Se recomienda efectivizar la transferencia de tecnología y conocimiento, pues todas estas acciones harán del transporte fluvial una actividad más segura, menos contaminante, generadora de turismo y empleo. Es necesario certificar a los operadores del transporte.

- Se sugiere que se defina una política de transporte fluvial en la que las tasas impositivas, tarifas, costos de mantenimiento de embarcaciones, derechos laborales, entre otros sean específicos de acuerdo a la zona de operación en procura del desarrollo del transporte fluvial en la Amazonía ecuatoriana.

- Las comunidades del área de influencia deben ser siempre partícipes del desarrollo local y empoderarse de los proyectos en esta línea, deben mantener la unidad y compromiso firme de consolidar alternativas de solución a los problemas de la navegación en sus propios territorios.

- Se recomienda que la academia y la comunidad concreten trabajos conjuntos a través de acuerdos en diferentes áreas, ya que es imprescindible conjugar la práctica, la teoría científica y empírica con la realidad. 


\subsection{Socialización de los resul- tados del proyecto}

Los resultados del proyecto de Navegabilidad del río Bobonaza se presentaron el 10 de marzo del 2013, ante los presidentes, kurakas, representantes de GAD's parroquiales, jefes de hogar, amas de casa y muchos más, en la localidad de Sarayacu.

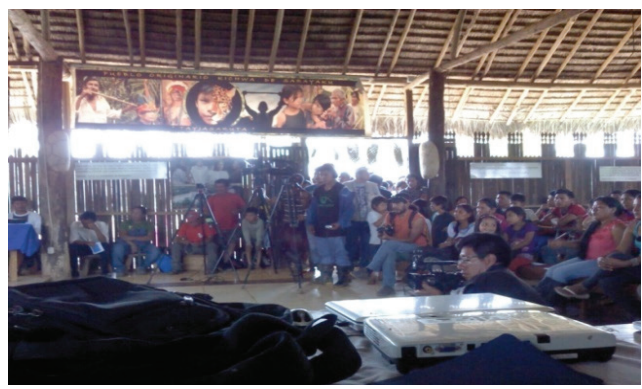

Fotografía 1.4. Socialización del Estudio en la comunidad de Sarayacu.

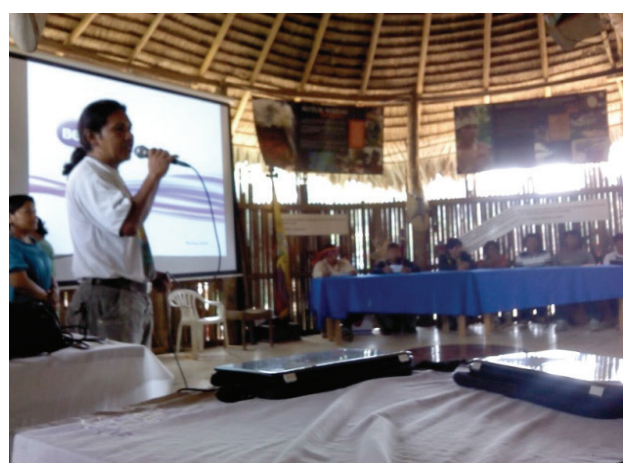

Fotografía 1.5. Socialización del Estudio en la comunidad de Sarayacu.

La Universidad Central del Ecuador, CETIF y el personal técnico consultor expresan su agradecimiento sincero, sentimientos de respeto y consideración a todos los representantes de las comunidades, juntas parroquiales, curacas, representantes de las diferentes nacionalidades indígenas, aso- ciaciones e instituciones públicas y privadas y personal de apoyo, que colaboraron en la realización del presente estudio, unidos por una causa común: lograr un futuro mejor.

\section{BIBLIOGRAFÍA}

ACOSTA, I. (2010), Herbario IMAS. AMIE, Archivo Maestro de Instituciones Educativas para el período lectivo 2010-2011.

AYALA, A. (2011). Características de Suelos, República Dominicana, disponible en: http://www.saintgobaincanalizacao.com.br /manual/solo.asp?lng=esp

BERNAL, T. César Augusto (2002). Metodología de la Investigación, Pearson educación, Colombia, Prensa Moderna.

BADILLO, E. (2005), Mecánica de Suelos, México, Limusa.

BONILLA, J. (2010). "Estudio de Impacto Ambiental para el Plan Maestro de Agua Potable para Puyo", Pastaza, Ecuador.

CODENPE, Consejo de Desarrollo de las Nacionalidades y Pueblos del Ecuador.

CHÁVEZ, Gina, LARA Romel, MORENO María (2005). "Sarayacu, El pueblo del cenit, identidad y construcción étnica: informe antropológico-jurídico sobre los impactos sociales y culturales de la presencia de la compañía CGC en Sarayaku", QuitoEcuador, FLACSO.

ECORAE (2007). Shimiyukkamu, Pastaza arkapaishkayshimiyachaytapushak, DIPEIB-P. CCE. ECORAE, Puyo, Ecuador.

ESPASA Calpe (2003). Derecho-economía, Enciclopedia del Conocimiento, Colombia.

ESPASA Calpe (2003). Geografía económica, Enciclopedia del Conocimiento, Colombia. 
Ediciones Rialp (1977). Técnica del Transporte, Enciclopedia Tecnología, Madrid, España.

GARCíA, José María (1970). Los Derechos Culturales como Derechos Humanos, Arias.

Ministerio de Cultura, España.

GARCíA, Sánchez J. y MAZA, Álvarez J. A. (1995). Cap. 11 del "Manual de Ingeniería de Ríos", México, Instituto de Ingeniería de la UNAM.

GADPP, Gobierno Autónomo Descentralizado Provincial de Pastaza, Reseña histórica, disponible en: www.pastaza.gob.ec/pastaza/canelos.

HOUTART, Francois, Ruth Casa (ed) (2011). El camino a la utopía y el bien común de la humanidad, La Paz, Bolivia.

HOUTART, Francois, Ruth Casa (ed.) (2006). Sociología de la religión, Editorial Buena Semilla, Bogotá, Colombia.

INAMHI (2012). Estación Meteorológica Puyo.

INEC (2010). VII Censo de Población y VI de Vivienda, Ecuador.

INEC, metodología expuesta en el Folleto de Pobreza y Desigualdad - ECV - Quinta, disponible en: http://www.inec.gob.ec/estadisticas/ Internationals develop Standard for products, systems and services used in construction, manufacturing and transportation ASTM, 2001. Disponible en http://www.saint-gobain-

canalizacao.com.br/manual/solo.asp?lng=esp
MOREANO, Alejandro (2011). Ciencias Sociales, revista de las carreras de Sociología y de Política de la Universidad Central del Ecuador, Quito.

ONU (2002). Naciones Unidas, "Informe sobre el cambio climático e inventario nacional de emisiones".

PAPANGU TURIS, Información disponible en www.papangutours.org/

Petroamazonas (2011). “Estudio de Impacto Ambiental y Plan de Manejo Ambiental para la Sísmica 3d del Bloque 31", Napo, Ecuador.

PETROPRODUCCIÓN. "Resumen ejecutivo del Estudio de Impacto Ambiental del Pozo de Desarrollo Auca Sur 3, campo auca" Región amazónica ecuatoriana.

ROCHA, Arturo. "Morfología fluvial y su incidencia en la estabilidad de obras viales".

SAMANIEGO, Rojas Edgar (2012). La Universidad y la Palabra, Quito, Ecuador, Editorial Universitaria.

RECIBIDO: 19 -noviembre-2013 ACEPTADO: 28 - noviembre - 2013

SARAYAKU, información disponible en: www.sarayaku.com; sarayaku.org

Secretaria Técnica de Hidrocarburos de Ecuador (SHE), (2012). Mapas Cartográficos, Pastaza, Ecuador.

SIG-CODENPE (2010). “Caracterización sistema ambiental de la nacionalidad achuar", provincia de Pastaza, Ecuador.

SIISE (2010). Sistema Integrado de Indicadores Sociales del Ecuador. 
UNDAET, Mario (2011). Cuatro años de revolución. Entre la propuesta y la realidad, Quito, Ecuador, FACSO,.

USFQ (2010). Centro de Transferencias y Desarrollo de Tecnologías, "Caracterización del Sistema Ambiental de Nacionalidades y Pueblos de Ecuador".

VELASCO Edwin (2011). "Sarayacu, un Estado dentro de otro Estado"? Red de Investigadores Iberoamericanos RII. Belo Horizonte-Brasil.

VELÁSQUEZ, Bejarano Teresa (2006). “Guía Metodológica para proyectos de protección y/o control de inundaciones en áreas agrícolas y urbanas".

Vicariato apostólico del Puyo, Cosmovisión Runa, Pastaza, sf. 